This is the peer reviewed version of the following article:

B. Ramírez-Barat, E. Cano „Agar vs agarose gelled electrolyte for in situ corrosion studies on metallic cultural heritage"ChemElectroChem 6, 2019, 2553-2559

which has been published in final form at http://dx.doi.org/10.1002/celc.201900344 . This article may be used for non-commercial purposes in accordance with Wiley Terms and Conditions for Use of SelfArchived Versions." 


\title{
Agar vs. agarose gelled electrolyte for in situ corrosion studies on metallic cultural heritage
}

\author{
Blanca Ramírez Barat ${ }^{*[a]}$ and Emilio Cano ${ }^{[a]}$
}

\begin{abstract}
The use of gelled electrolytes has revealed as an interesting solution for in situ electrochemical measures on cultural heritage, where liquid electrolytes cannot be easily handled. After developing an agar gelled electrolyte cell, other gelling agents as agarose are being considered to improve it. In this work, the performance of agarose gels in different concentrations has been studied and compared to agar and a liquid electrolyte. Measurements have been done on patinated quaternary bronze and weathering steel, as representative materials of outdoor monuments. Agarose gels have been validated for in situ corrosion studies on bronze and weathering steel sculptures.
\end{abstract}

\section{Introduction}

Development of new and improved diagnostic tools is a relevant subject in conservation science, and the application of electrochemical techniques has become an outstanding topic in recent years for the assessment of patinas and protective coatings for metallic heritage ${ }^{11}$. The unique nature of the objects, their irreplaceable value, the long-term evolution of patinas and corrosion products (which cannot be reproduced in the laboratory) and the requirement of conservators-restorers to have scientific evidence to support decisions on conservation treatments make necessary to carry out in-situ scientific analysis on the real heritage artefacts. The practical difficulties of doing in-situ electrochemical measurements has restrained the use of these techniques for conservation science [2].

In this particular area, different authors have worked in the design of a solid electrolyte cell for in situ electrochemical measurements, where handling liquid electrolytes offers several difficulties. Commercial electrocardiogram electrodes ${ }^{[3]}$, synthetized anionic gels ${ }^{4]}$, agar gelled electrolytes ${ }^{[5]}$ or PVA ${ }^{6]}$ have been proposed for this purpose. The properties of the electrolyte together with the geometric design are the design key features, particularly for in situ studies.

The use of agar gelled electrolytes has recently been evaluated by different authors [7] showing that agar cells offer good performance and interesting properties for this purpose. Agar is a translucent, cheap, non-toxic, and quick and easy to prepare material, which admits a wide range of aqueous electrolytes and

[a] B. Ramirez Barat BA, BSc, MSc, E. Cano, PhD National Center for Metallurgical Research (CENIM) Spanish National Research Council (CSIC) Avda. Gregorio del Amo 8, 28040 Madrid blanca.ramirez@csic.es also contributes to conductivity. It's flexibility allows adaptation to irregular surfaces and can be improved by the addition of plasticizers $\left.{ }^{[7 d,}, \underline{e}\right]$, and its syneresis helps wetting the surface and allowing good contact. Other proposed materials, have shown other limitations: Commercial or synthetized anionic gels are very limited by the electrolyte choice, and the use of PVA has to be more deeply studied, as preliminary results showed appreciable differences when compared to a traditional cell design. In previous studies agar showed a certain decrease in impedance values if compared to the liquid electrolyte, which was attributed to some anodic depolarizing effect in bronze, slightly increasing the measured corrosion rate if compared to a traditional liquid electrolyte. Though this effect can be minimized using low agar concentrations and it is not a problem for comparative studies $[76$, 7c], further improvements of the measuring system were considered.

Agar is a mixture of two polysaccharides: agarose, which is the neutral fraction, and agaropectin, modified by side groups. As this later seems to be the responsible for the interaction with copper ions, which accelerates the anodic reaction, the most intuitive approach to avoid this effect is the use of pure agarose instead of agar. Agarose may have same advantages as agar, while its neutral chemical nature will reduce the risk of undesired interactions with metal ions, effects that may be attributed to the agaropectin fraction. Another potential advantage of agarose is that being a purer and homogeneous substance, it is foreseeable to obtain consistent results between different commercial products, while agar may show differences according to its provenance.

A review of literature shows that other researchers have already suggested the use of agarose as a solid medium for conventional electrochemical measurements although very few articles have been published. Kaneko and co-workers studied the use of agarose gels as an electrolyte for electrochemical measurements, such as Electrochemical Impedance Spectroscopy or Voltammetry, providing similar results to liquid electrolytes [8] These authors evaluated transport and electrochemical properties of agarose gels, finding out that were very close to aqueous systems. Despite the interest of this work, to our best knowledge, no application of agarose to corrosion studies has been done. For this reason, the aim of this work is to evaluate the behaviour and applicability of agarose gelled electrolytes for corrosion studies in cultural heritage, in comparison with both a liquid electrolyte and with agar-based electrolyte, which has demonstrated its utility for in-situ measurements. Measurements have been done with the gel polymer electrolyte (G-PE) cell described in previous papers $[5, \underline{7 c}, \underline{9}$, under the experimental conditions presented in "Experimental Section". As base electrolyte, an artificial rain (AR) solution has been used, both as liquid and gelled with agar and agarose. 


\section{Results and Discussion}

\section{Agarose as a gelling agent}

The behaviour of the agarose gelled electrolyte has been studied over different substrates and compared with the liquid electrolyte and agar-gelled electrolyte. These include bare metal surfaces, artificially and naturally patinated metals and coated metals: AISI316 stainless steel has been chosen as reference material, and patinated cast bronze and weathering steel, as representative materials of outdoor sculptures.

Figure 1 shows EIS spectra for the liquid, agarose-gelled and agar-gelled electrolyte obtained on stainless steel coupons. The high stability and uniformity of the passive layer formed on the stainless steel allows a precise comparison of the contribution of the different experimental setups ${ }^{[9]}$ For this system, agarose and liquid results are almost identical, and differences appear only for agar and in the high frequency region. This difference can explained by the lower electrolyte resistance, due to the agar's increase of conductivity [5]

In the case of weathering steel (figure 2) a decrease in the impedance of intermediate frequencies is also observable for agar, while results from liquid and agarose electrolyte can be considerate almost equivalent. Due to the inhomogeneity of natural patinas in weathering steels, it is difficult to ascertain to which extent this effect is attributable to differences in the samples or to the effect of the composition of the electrolyte.

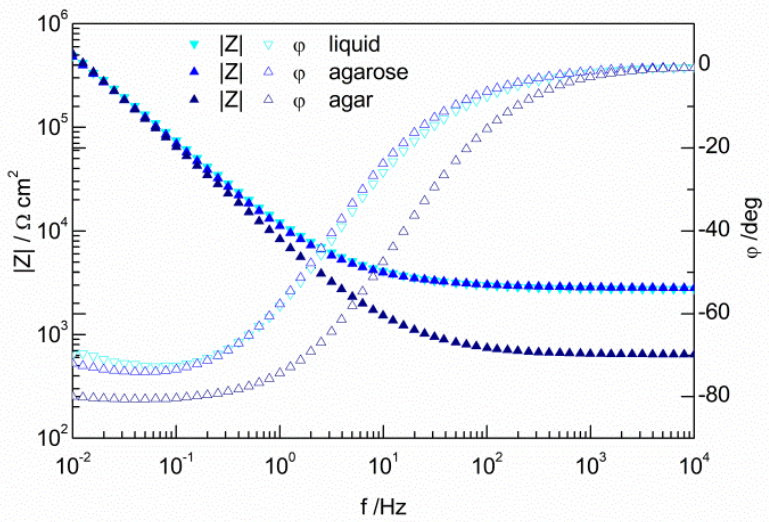

Figure 1. EIS spectra (Bode plot) obtained with liquid electrolyte, agarose and agar gels on AISI316 stainless steel.

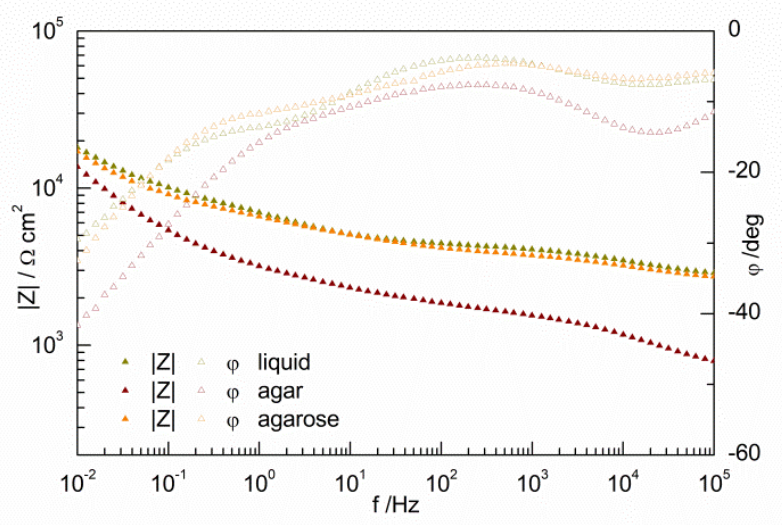

Figure 2. EIS spectra (Bode plot) obtained with liquid electrolyte, agarose and agar gels on weathering steel (three year natural patina).
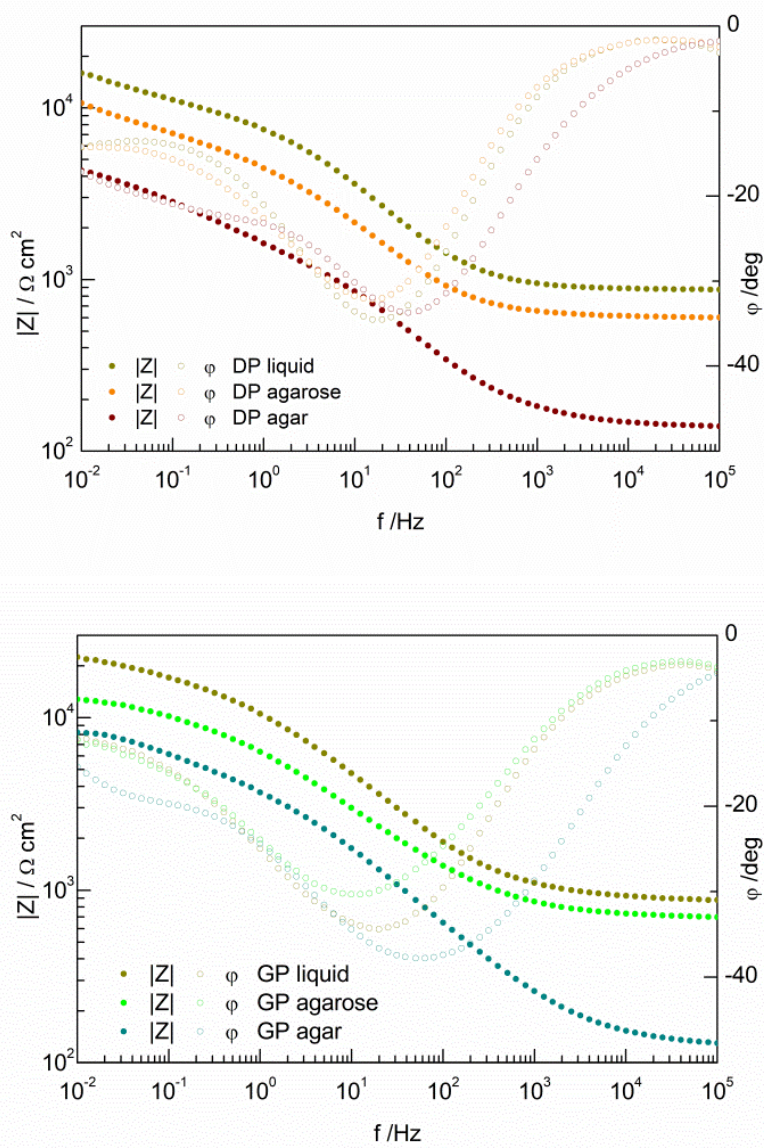

Figure 3. EIS spectra (Bode plot) obtained with liquid electrolyte, agarose and agar gels on cast bronze with dark and green patina. 

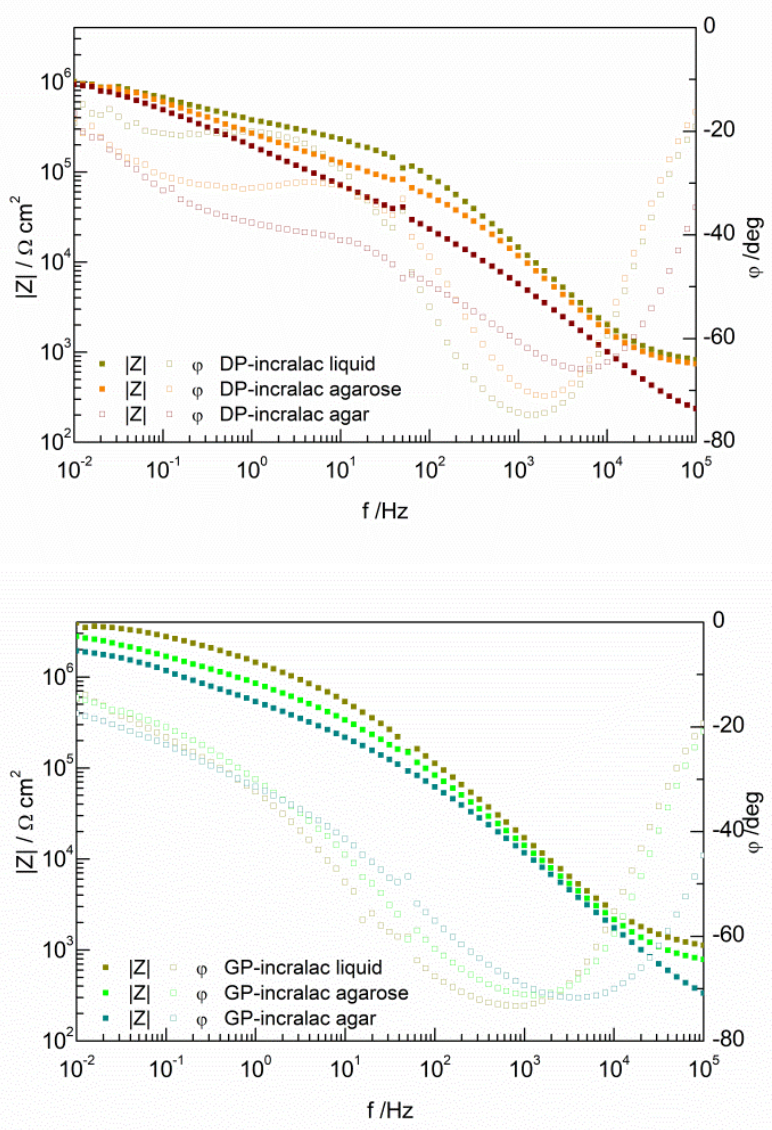

Figure 4. EIS spectra (Bode plot) obtained with liquid electrolyte, agarose and agar gels on Incralac coated bronze with dark and green patina.

When measures are done on bronze (Figure 3), there is also a drop in impedance's value at low frequencies, together with a phase angle shift. This effect, which is slightly present in the agarose gel too, has been related to the interaction between copper ions and the gel matrix [7c]. When bronze is covered by a protective coating as Incralac ${ }^{\circledR}$ (figures 4 ) this effect is minimized, and results obtained with the three electrolytes are comparable, taking into account that the measured surfaces are not identical (as have been individually prepared by hand, following the common practice of conservators-restorers in conservation treatments for real objects).

In general, it can be appreciated that EIS spectra obtained with agarose are quite similar to those acquired with the liquid electrolyte, while measurements with agar show lower impedances, especially at high frequencies. These differences are more or less pronounced depending on the working electrode material.

\section{Agar vs agarose in field measurements}

Since the final aim of the G-PE cell is the in-situ electrochemical measurements on metallic heritage, the comparison of agar and agarose gelled electrolyte was done by field measurements on five different bronze and weathering steel sculptures, at different locations. The five sculptures where a bronze Sphinx at the National Archaeological Museum in Madrid, with an Incralac $\AA$ coating; a bronze angel figure by Enrico Astorri from the Staglieno monumental cemetery in Genoa; a modern bronze sculpture, Unidad Yunta (Pablo Serrano, 1970) at the Polytechnic University of Valencia and two weathering steel sculptures located at the Museo de Escultura de Leganés (Madrid): Templo (2003) by Adriana Veyrat and Zenon (1980) by José Luis Sánchez (owned by Museo Reina Sofía).

In all cases, apart from the higher conductivity of agar, EIS spectra are very similar for agar and agarose in all examples, as can be appreciated in figures 6-8. Measures on the Angel figure, with a thick highly washed patina, and Zenon, with a welldeveloped and smooth patina, are almost identical for the two gelled electrolytes. Comparing the values of the low frequency limit of the impedance modulus (table 1), it can be appreciated that values are very close for every couple of measurements (agar-agarose) on the same sculpture. The fact that in some cases agarose yield lower impedance and in other higher suggest that differences may be attributed to small patina inhomogeneity and/or differences in the wetted area, which in this in-situ measurements are higher than the differences due to the electrolyte that have been demonstrated in previous section. The largest differences seem to appear in one of the weathering steel sculptures, Templo, the one with the younger and presumably thinner patina, but numerical differences are in fact very little though visual differences seem higher due to the scale of the graph. The higher difference when comparing values is in the coated bronze surface from the bronze Sphinx.

From these results, it can be considered that differences between both electrolytes in field measurements are not quite relevant. This difference with laboratory measurements can be explained by the fact that laboratory coupons are more homogeneous and uniform, and are more reactive than patinas of outdoor sculptures which have been exposed and washed through many years.

Table 1. Comparison of the impedance modulus at the low frequency limit with agar and agarose gelled electrolyte for different sculptures.

\begin{tabular}{lcccccc}
\hline \multicolumn{7}{c}{$|\mathrm{Z}|_{\max } \mathrm{Ohm} \mathrm{cm}{ }^{2}$} \\
\hline \\
$\begin{array}{c}\text { Angel } \\
\text { (green } \\
\text { area) }\end{array}$ & $\begin{array}{c}\text { Angel } \\
\text { (black } \\
\text { area) }\end{array}$ & Sphinx & $\begin{array}{c}\text { Unidad } \\
\text { Yunta }\end{array}$ & Templo & Zenon \\
& & & & & \\
\hline agar & $1.50 \mathrm{E}+05$ & $6.83 \mathrm{E}+04$ & $3.89 \mathrm{E}+05$ & $3.45 \mathrm{E}+05$ & $9.44 \mathrm{E}+03$ & $1.57 \mathrm{E}+06$ \\
agarose & $1.26 \mathrm{E}+05$ & $8.12 \mathrm{E}+04$ & $6.02 \mathrm{E}+05$ & $2.78 \mathrm{E}+05$ & $9.81 \mathrm{E}+03$ & $1.93 \mathrm{E}+06$ \\
\hline
\end{tabular}



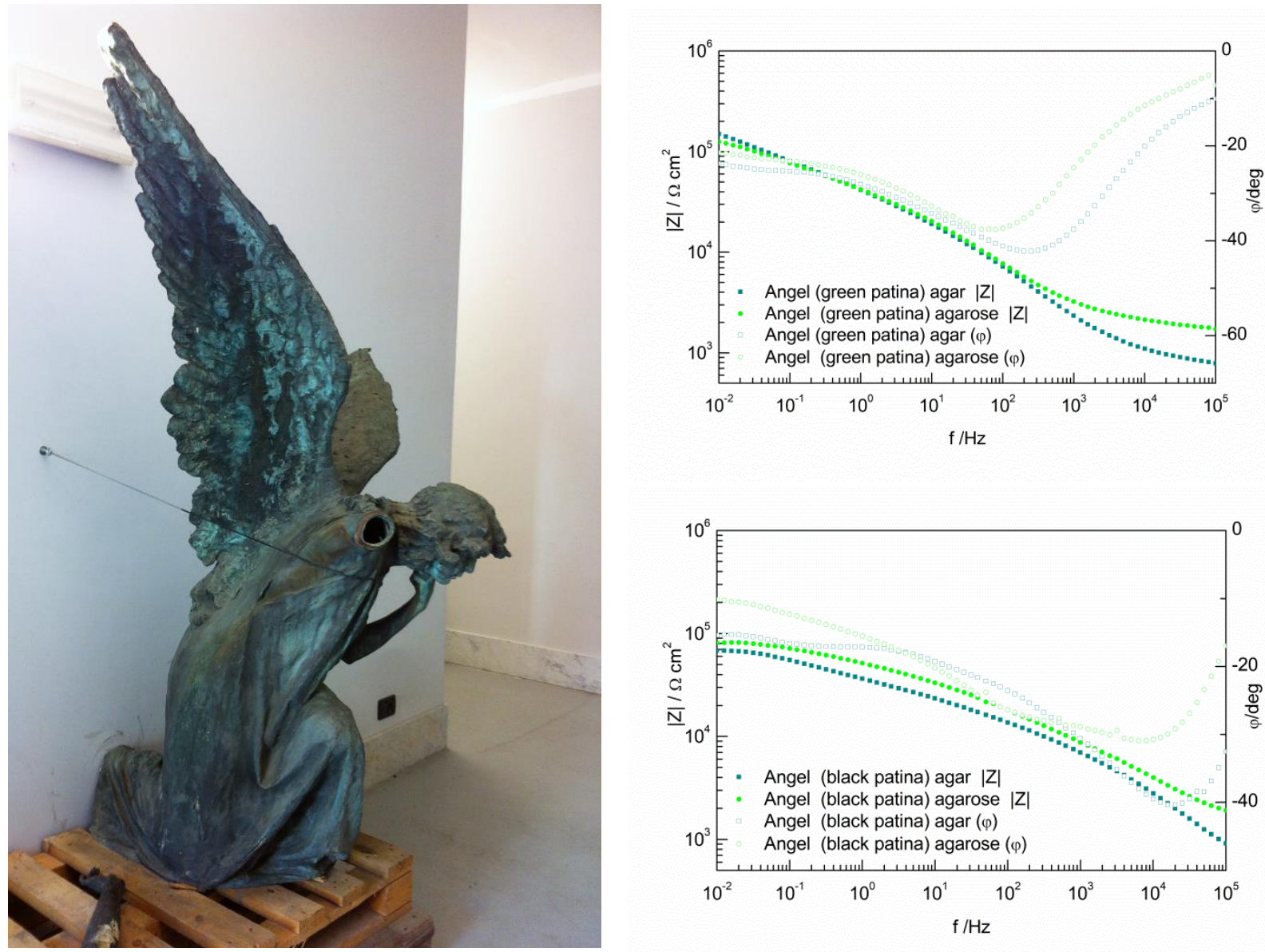

Figure 5. Bode plot from a bronze angel, by Enrico Astorri (1859-1921) at the Staglieno cemetery in Genoa. Spectra from green and black areas on the left arm.
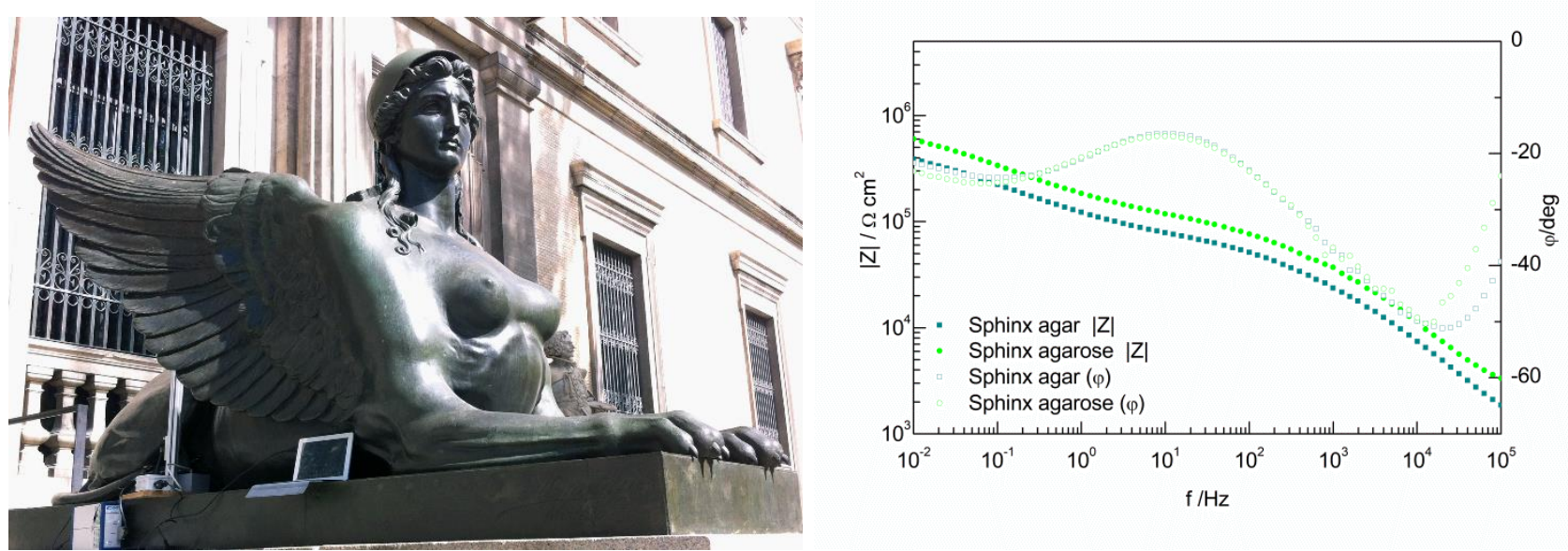

Figure 6. Bode plot of the right sphinx at the main façade of the National Archaeological Museum in Madrid. The Sphinxes, casted in 1894, were restored and protected with Incralac $\AA$ and wax a couple of years before $[7 b, 10]$. 

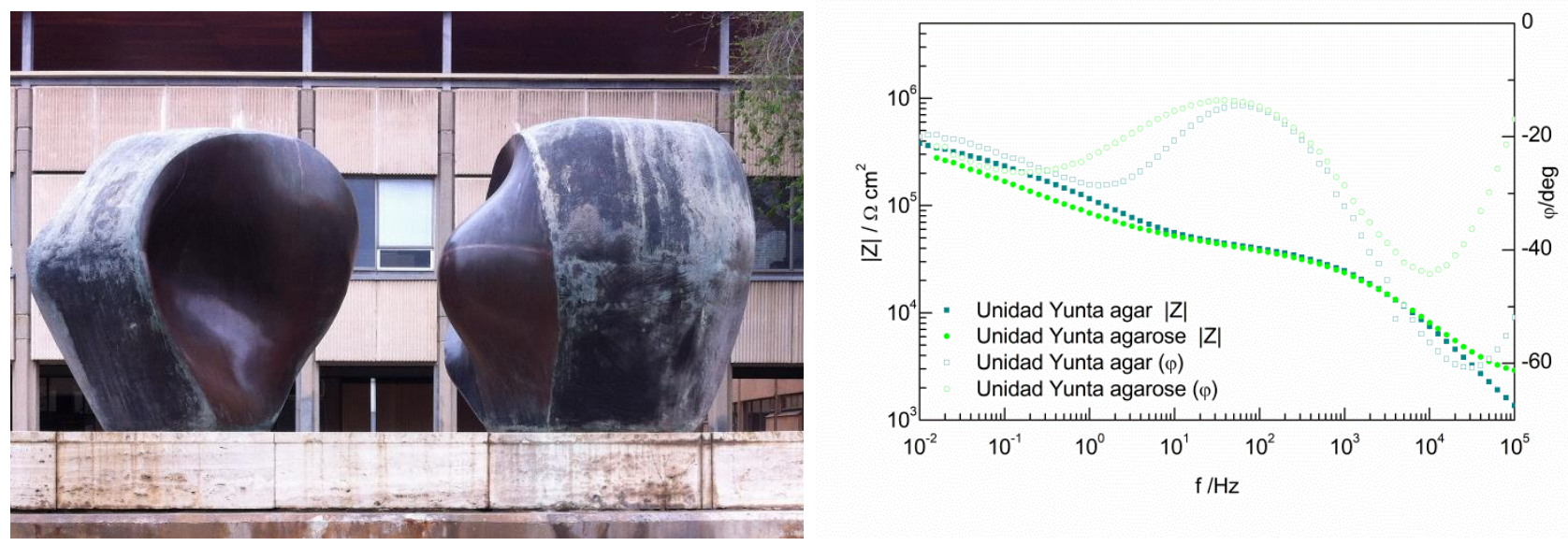

Figure 7. Bode plot of a modern bronze sculpture, Unidad Yunta (1970) by Pablo Serrano, on the brown polished area.
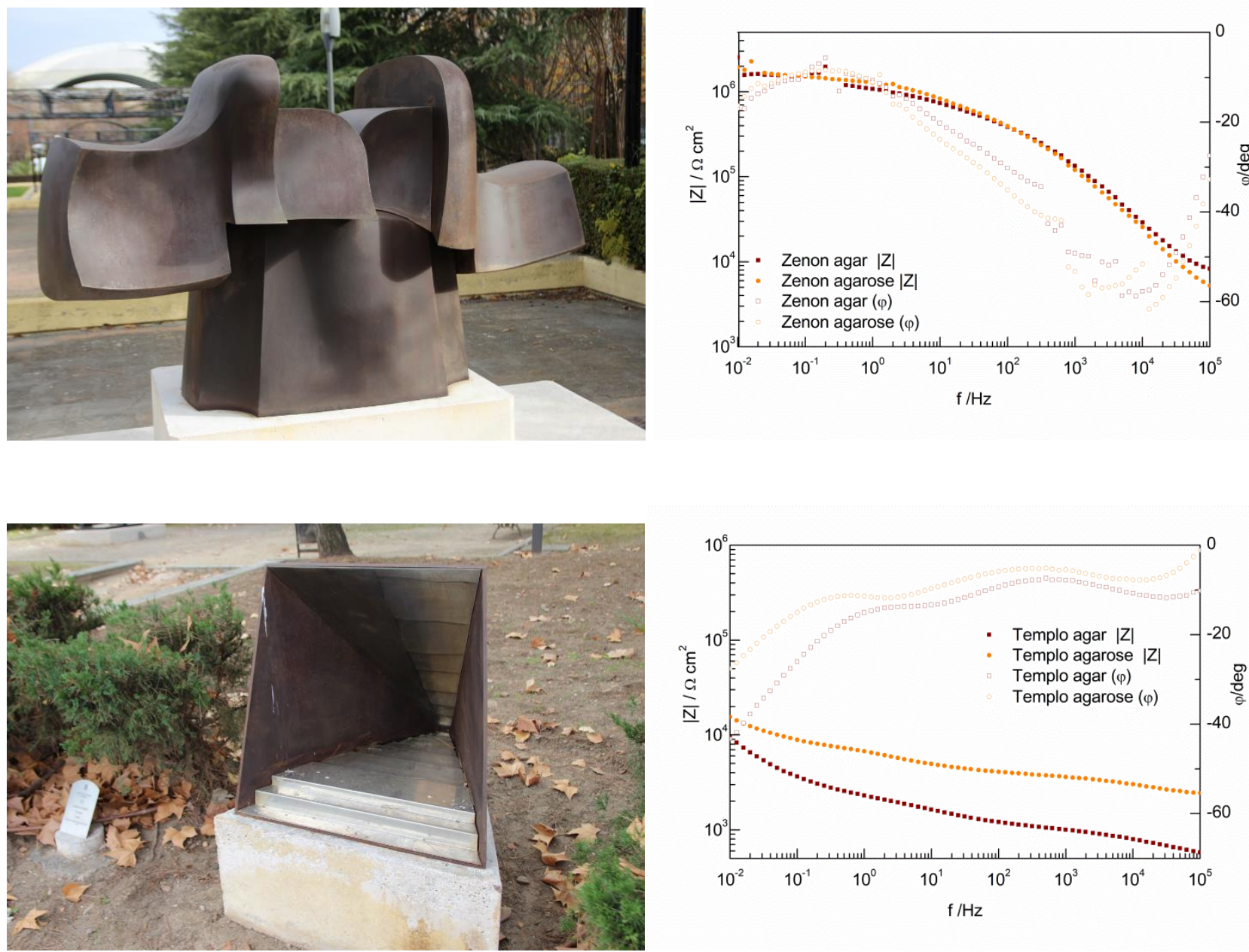

Figure 8. EIS spectra (Bode plot) on weathering steel sculptures at the Museo de Escultura de Leganés. Zenon (1980), by José Luis Sánchez, a weathering steel sculpture with a waxed and polished surface and Templo (2003), by Adriana Veyrat, with a thin lepidocrocite patina [11] 


\subsection{Agarose concentration}

As previously noted, the choice of $2 \%$ agarose was based on the fact that this would be the equivalent to $3 \%$ agar, so this concentration could be compared with previous results obtained with the agar cell. As shown in previous sections, $2 \%$ agarose gave spectra closer to liquid electrolyte than agar, though still showed a slightly lower impedance values in the more reactive bronze surfaces. Considering that results may be improved using a different agarose concentration, a series of EIS measurements at different agarose percentages were done on the two reference materials, patinated bronze (figure 9) and weathering steel (figure $10)$, and compared to the liquid electrolyte

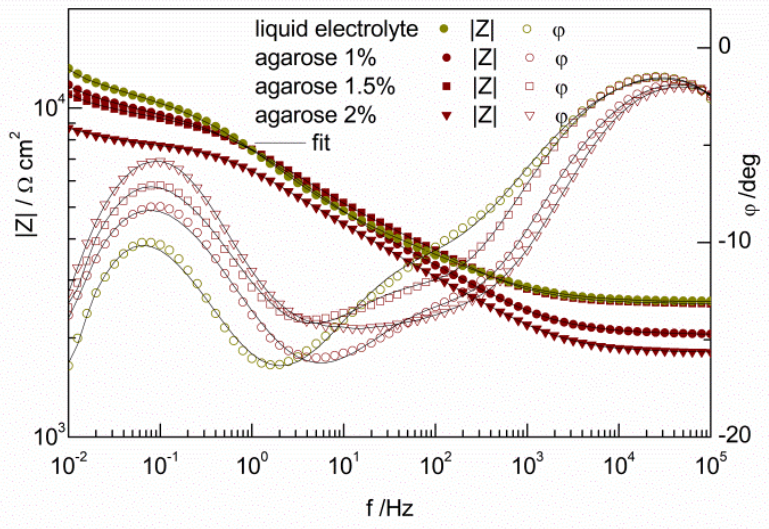

Figure 9. EIS spectra of brown patinated bronze coupons with different agarose concentrations.

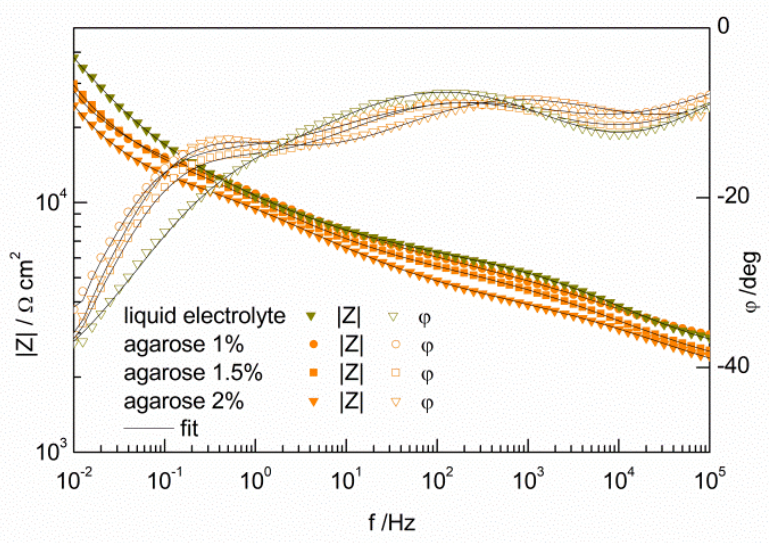

Figure 10. EIS spectra of 5 years aged weathering steel with different agarose concentrations.

Though the lower is the agarose concentration more close is the EIS spectra to the liquid electrolyte, differences between agarose concentrations are relatively small. Table 2 shows the different electrolyte concentrations, $\mathrm{pH}$ and conductivity. The addition of agarose to the liquid electrolyte slightly increases the conductivity and does not modify the $\mathrm{pH}$ value, while agar produced more basic $\mathrm{pH}$ and significantly enhances conductivity, as previously described ${ }^{7 \mathrm{Cc}}$. As with agar, this increase in conductivity explains the lower $|\mathrm{Z}|$ values at high frequencies with the increasing concentration of agarose, but this effect is quite small, especially when compared with agar, so it can usually be disregarded. Considering these small variations, other effects, such as geometrical factors can be responsible for slight variations in high frequencies $|Z|$ values in figures 9 and 10: as Rs depends on the area and WE-RE distance, small variations due to the deformation of the gel when pressured to the working electrode surface, can explain this behaviour. This is specially the case of the lower concentrations $(1 \%)$, which produce a very soft gel, with low mechanical resistance.

Table 2 Different electrolyte concentrations, $\mathrm{pH}$ and conductivity

\begin{tabular}{lll}
\hline electrolyte & $\mathrm{pH}$ & Conductivity $(\mathrm{mS})$ \\
\hline AR & 6.67 & 94.0 \\
AR-agarose 1\% & $6.7 \pm 0.2$ & $120 \pm 2$ \\
AR-agarose 1.5\% & $6.5 \pm 0.2$ & $126 \pm 6$ \\
AR-agarose 2\% & $6.6 \pm 0.2$ & $132 \pm 6$ \\
AR-agar 3\% & $7.42 \pm 0.03$ & $1524 \pm 15$ \\
\hline
\end{tabular}

In order to elucidate the contribution of agarose to the EIS spectra at other frequencies, results were fitted to the general equivalent circuit presented in figure 11. The use of this circuit has been discussed in a previous paper [1]. Rs is the resistance of the electrolyte, CPE1-R1 represent the resistance and capacitance of the patina or rust layer, CPE2-R2 the capacitance of the double layer at the metal-electrolyte interface and charge transfer resistance of the redox reactions and $\mathrm{W}$ represents diffusive effects related to copper ions diffusion in the patina for bronze ${ }^{[12}$ and to oxygen diffusion through the pores in the rust layer, in the case of steel [13].

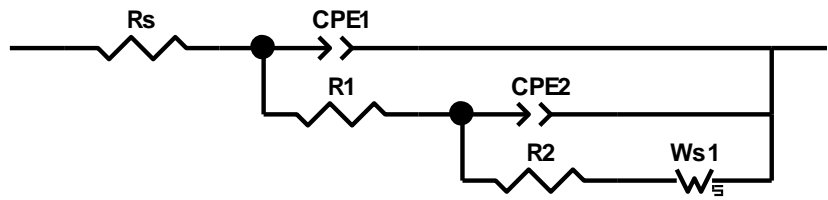

Figure 11. Equivalent circuit used for modelling EIS spectra of patinated metal coupons.

The values obtained for the different elements (Table 3 ) are also very close, moreover taking into account the irregularities of the patina surfaces and the unavoidable uncertainty in the measured area, in particular for the highly porous and absorbing rust layer in weathering steel. The values of $\mathrm{R} 2$ seem to decrease slightly with the increasing concentration of agarose, both for bronze and 
Table 3. Fit results of EIS spectra on bronze and weathering steel coupons for different agarose concentrations compared to the liquid electrolyte.

\begin{tabular}{|c|c|c|c|c|c|c|c|c|c|c|}
\hline \multirow{2}{*}{ Bronze } & \multirow{2}{*}{$\begin{array}{c}\text { Rs } \\
\left(\mathrm{k} \Omega \cdot \mathrm{cm}^{2}\right)\end{array}$} & \multicolumn{2}{|c|}{ CPE 1} & \multirow{2}{*}{$\begin{array}{c}R 1 \\
\left(k \Omega \cdot \mathrm{cm}^{2}\right)\end{array}$} & \multicolumn{2}{|c|}{ CPE 2} & \multirow{2}{*}{$\begin{array}{c}\mathrm{R} 2 \\
\left(\mathrm{k} \Omega \mathrm{cm}^{2}\right)\end{array}$} & \multicolumn{3}{|c|}{ W } \\
\hline & & $\begin{array}{c}Y_{1} \\
\left(S s^{\alpha 1} \mathrm{~cm}^{-2}\right)\end{array}$ & $\alpha_{1}$ & & $\begin{array}{c}Y_{2} \\
\left(S \mathrm{~s}^{\alpha 2} \mathrm{~cm}^{-2}\right)\end{array}$ & $\alpha_{2}$ & & $\begin{array}{c}R \\
\left(\mathrm{k} \Omega \cdot \mathrm{cm}^{2}\right)\end{array}$ & $T(s)$ & $\alpha_{w}$ \\
\hline Liquid & 2.6 & 7.5E-06 & 0.64 & 1.8 & $5.1 \mathrm{E}-05$ & 0.58 & 7.4 & 17.1 & 123 & 0.72 \\
\hline $1 \%$ & 2.0 & 3.7E-06 & 0.69 & 1.7 & 4.2E-05 & 0.55 & 6.6 & 13.4 & 140 & 0.67 \\
\hline $1.5 \%$ & 2.5 & 4.7E-06 & 0.69 & 2.0 & 4.7E-05 & 0.58 & 5.4 & 11.6 & 117 & 0.72 \\
\hline \multirow{2}{*}{ W. steel } & \multirow{2}{*}{$\begin{array}{c}\text { Rs } \\
\left(\mathrm{k} \Omega \cdot \mathrm{cm}^{2}\right)\end{array}$} & \multicolumn{2}{|c|}{ CPE 1} & & \multicolumn{2}{|c|}{ CPE 2} & & \multicolumn{3}{|c|}{ w } \\
\hline & & $\begin{array}{c}Y_{1} \\
\left(S \mathrm{~s}^{\alpha 1} \mathrm{~cm}^{-2}\right)\end{array}$ & $\alpha_{1}$ & $\left(\mathrm{k} \Omega \cdot \mathrm{cm}^{2}\right)$ & 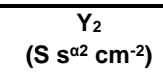 & $\alpha_{2}$ & $\left(\mathrm{k} \Omega \mathrm{cm}^{2}\right)$ & $\begin{array}{c}R \\
\left(k \Omega \cdot \mathrm{cm}^{2}\right)\end{array}$ & $T(s)$ & $\alpha_{w}$ \\
\hline Liquid & 2.3 & 1.35E-06 & 0.51 & 4.0 & 5.5E-05 & 0.48 & 10.4 & 138 & 80 & 0.54 \\
\hline $1 \%$ & 2.3 & 3.3E-06 & 0.44 & 3.7 & $6.0 \mathrm{E}-05$ & 0.40 & 16.9 & 152 & 120 & 0.75 \\
\hline $2 \%$ & 1.7 & 2.1E-06 & 0.46 & 2.5 & 4.2E-05 & 0.44 & 10.6 & 107 & 146 & 0.70 \\
\hline
\end{tabular}

weathering steel. This indicates that agarose slightly increases the measured corrosion rate, although this effect is much less relevant than for agar ${ }^{[7 \mathrm{c}]}$. Diffusion does not seem to be affected by the use of the gel in the case of bronze, in agreement with a previous work ${ }^{[7 \mathrm{c}]}$, but for weathering steel the diffusive impedance is increased, what might be explained by the lower oxygen content of gelled electrolytes [7d]. In any case, as it has been shown in the results of previous section (Figs. 5-8), the uncertainties of field measurements are higher than these effects.

For this reason, the use and concentration of agarose does not present a critical issue for in situ corrosion studies in cultural heritage. As a compromise between mechanical and electrochemical properties, $1.5-2 \%$ agarose would be a good option.

\section{Conclusions}

Agarose has shown to be a good option for electrochemical measurements on cultural heritage objects, where a conventional cell cannot be used and the use of gel electrolytes can offer many advantages.

Results show that agarose gives a response quite close to the liquid electrolyte, thus it is a good option to carry out corrosion studies, where agar may have a higher effect on results. This would be the case of reactive surfaces as non-aged coupons or fresh patinas.

Field measurements on long-term weathered surfaces of monuments or in coated metals do not show significant differences between the two gelled electrolytes, so the use of agar is still valid if necessary. The natural conductivity of agar may offer an additional advantage in field measurements, especially for low impedance patinas such as those of weathering steels.

\section{Experimental Section}

As mentioned in the introduction, measurements have been done with the gel polymer electrolyte (G-PE) cell designed by authors and described in detail in references $[\underline{5}, \underline{7 c}, \underline{9}$.

The electrolyte has been prepared by gelling a liquid electrolyte with agar (technical grade) or agarose (basic, Panreac). As liquid electrolyte concentrated artificial rain $\left(\mathrm{CaSO}_{4} \cdot 2 \mathrm{H}_{2} \mathrm{O} 14.43 \mathrm{mg} / \mathrm{mL},\left(\mathrm{NH}_{4}\right)_{2} \mathrm{SO}_{4} 15.04\right.$ $\mathrm{mg} / \mathrm{mL},\left(\mathrm{NH}_{4}\right) \mathrm{Cl} 19.15 \mathrm{mg} / \mathrm{mL}, \mathrm{NaNO}_{3} 15.13 \mathrm{mg} / \mathrm{mL}$ and $\mathrm{CH}_{3} \mathrm{COONa} 3.19$ $\mathrm{mg} / \mathrm{mL}$ ) has been used, adapted from [14]. The solution is prepared 1000 fold concentrated and $\mathrm{pH}$ adjusted to 5 with $\mathrm{HNO}_{3}$ and stored at room temperature. For the measurements, this solution is then diluted to a 10 fold concentration, with a final $\mathrm{pH}$ value of 6.5 . This solution has been chosen because it has a similar composition to the natural electrolyte to which outdoor monuments are exposed and at the same time it is a mild electrolyte which prevents any damage to the surface. To prepare the electrolyte $3 \% \mathrm{w}-\mathrm{v}$ agar or $1-2 \% \mathrm{w}-\mathrm{v}$ agarose powder is added to the electrolyte in a beaker and gently heated in a microwave oven at low power until dissolution. The solution is poured into the mould and left to cool at room temperature. For comparison between agar and agarose gels, $2 \%$ agarose was used. As agarose represents two thirds of agar composition, $2 \%$ agarose would be the equivalent to the $3 \%$ agar gel used in previous work. A stainless steel wire (AISI 316L) has been used as pseudoreference electrode and a spiral made of the same material has been employed for the counter electrode (CE). In all cases, the geometry of the cell and electrode positions have been kept constant.

The behaviour of the different electrolyte compositions has been tested on AISI316 stainless steel coupons and on patinated cast bronze and weathering steel, as representative materials of outdoor sculptures. Different sets of reference coupons were used, prepared as:

- Quaternary (85 Cu, 5 Sn, 5 Pb, 5 Zn \%w) EN 1982CC491K (DIN 1705-RG5) cast bronze coupons were prepared by a traditional Spanish foundry according to traditional methods for artistic sculpture. Samples were cast, sand blasted and artificially patinated with a dark patina (using a potassium sufide solution) and a green patina (using an ammonium 
chloride solution). Patination solutions were applied by alternatingly brushing the solution on the metallic surface and heating with a torch. One layer of Incralac $\AA$, an acrylic coating used in conservation treatments of bronze sculptures, was applied by brush on some coupons.

- Weathering steel (Arcelor S355J2W, EN 10025-5-2004) with a natural patina developed by exposing the steel coupons to a mild urban atmosphere (Madrid, Spain) for 3 and 5 years in an atmospheric corrosion station (according to standard ISO 8565:1992).

- AISI 316 stainless steel has been used as a highly stable reference material, to minimize the effects of inhomogeneity in patina layers. Stainless steel coupons have been polished for homogenization of the surface and left to the air for several days to allow the formation of its natural passivation layer.

EIS spectra have been acquired using a Gamry 600 Potentiostat, using a frequency swept from $100 \mathrm{kHz}$ to $10 \mathrm{mHz}, 10 \mathrm{mV}$ RMS amplitude (at the open circuit potential, OCP) and 10 points/ decade. The area exposed to the electrolyte was $3.14 \mathrm{~cm}^{2}$. Analysis of the data has been carried out using ZView software. The system was left to stabilize at OCP for 30 minutes before measurements. Conductivity and $\mathrm{pH}$ of the electrolytes has been measured with a Crison MM40 conductimeter/pHmeter.

\section{Acknowledgements}

This work was supported by the Spanish Ministerio de Economía y Competividad (projects HAR2011-22402 and HAR2014-54893$\mathrm{R}$, and grant BES-2012-052716), Comunidad de Madrid and European Union (Programa TOP Heritage-CM, P2018/NMT4372). Authors want to acknowledge Museo de Escultura de Leganés, Museo Nacional Centro de Arte Reina Sofía, Museo Arqueológico Nacional, Universidad Politécnica de Valencia, Paola Letardi and Cimitero di Staglieno (Genoa) and the Spanish Network TechnoHeritage.

Keywords: agarose $\cdot$ corrosion $\bullet$ cultural heritage $\bullet$ EIS $\cdot$ gel electrolyte

\section{References}

[1] B. Ramírez Barat, E. Cano, ChemElectroChem 2018, 5, 2698-2716.

[2] a) E. Cano, D. Lafuente, D. M. Bastidas, Journal of Solid State Electrochemistry 2010, 14, 381-391; b) E. Cano, D. M. Bastidas, V. Argyropoulos, S. Fajardo, A. Siatou, J. M. Bastidas, C. Degrigny, Journal of Solid State Electrochemistry 2010, 14, 453-463.

[3] E. Angelini, S. Grassini, S. Corbellini, G. M. Ingo, T. De Caro, P. Plescia C. Riccucci, A. Bianco, S. Agostini, Applied Physics A: Materials Science and Processing 2006, 83, 643-649.

[4] A. H. England, T. L. Clare, Electroanalysis 2014, 26, 1059-1067.

[5] E. Cano, A. Crespo, D. Lafuente, B. Ramírez Barat, Electrochemistry Communications 2014, 41, 16-19.

[6] F. Di Turo, P. Matricardi, C. Di Meo, F. Mazzei, G. Favero, D. Zane, Journal of Cultural Heritage 2018.

[7] a) B. Ramírez Barat, E. Cano, P. Letardi, Sensors \& Actuators: B. Chemical 2018, 261, 572-580; b) B. Ramírez Barat, A. Crespo, E. García, S. Díaz, E. Cano, Journal of Cultural Heritage 2017, 24, 93-99; c) B. Ramírez Barat, E. Cano, Electrochimica Acta 2015, 182, 751-762; d) G. Monrrabal, B. Ramírez-Barat, A. Bautista, F. Velasco, E. Cano, Metals 2018, 8; e) G. Monrrabal, S. Guzmán, I. E. Hamilton, A. Bautista, F. Velasco, Electrochimica Acta 2016, 220, 20-28; f) F. Di Turo, C. De Vito, F. Coletti, F. Mazzei, R. Antiochia, G. Favero, Microchem. J. 2017, 134, 154-163.

[8] a) H. Ueno, Y. Endo, Y. Kaburagi, M. Kaneko, Journal of Electroanalytical Chemistry 2004, 570, 95-100; b) N. Mochizuki, H. Ueno, M. Kaneko, Electrochimica Acta 2004, 49, 4143-4148; c) H. Ueno, M. Kaneko, Journal of Electroanalytical Chemistry 2004, 568, 87-92.

[9] B. Ramírez Barat, E. Cano, P. Letardi, Sensors and Actuators, B: Chemical 2018, 261, 572-580.

[10] S. Díaz Martínez, Boletín del Museo Arqueológico Nacional 2015, 33 267-283.

[11] A. Crespo, B. Ramírez Barat, I. Diaz Ocaña, E. Cano Díaz, in Conservación de Arte Contemporáneo 18 $8^{\underline{a}}$ Jornada (Ed.: M. Departamento de Conservación-Restauración), 2017, pp. 193-201.

[12] Y. Feng, W. K. Teo, K. S. Siow, K. I. Tan, A. K. Hsieh, Corrosion Science 1996, 38, 369-385

[13] a) J. H. Wang, F. I. Wei, H. C. Shih, Corrosion 1996, 52(12), 900-909; b) J. H. Wang, F. I. Wei, H. C. Shin, Corrosion 1996, 52(8), 600-608.

[14] E. Bernardi, C. Chiavari, C. Martini, L. Morselli, Applied Physics A Materials Science and Processing 2008, 92, 83-89. 
Entry for the Table of Contents (Please choose one layout)

Layout 1:

\section{ARTICLE}

Electrolyte gels to study non flat surfaces of monuments: The use of agarose gelled electrolytes for in situ EIS measurements on cultural heritage objects is explored.

Agarose is compared to agar and liquid electrolytes, showing that its behaviour is closer to liquid electrolytes on metal coupons, though differences between gels are small in outdoor weathered surfaces.

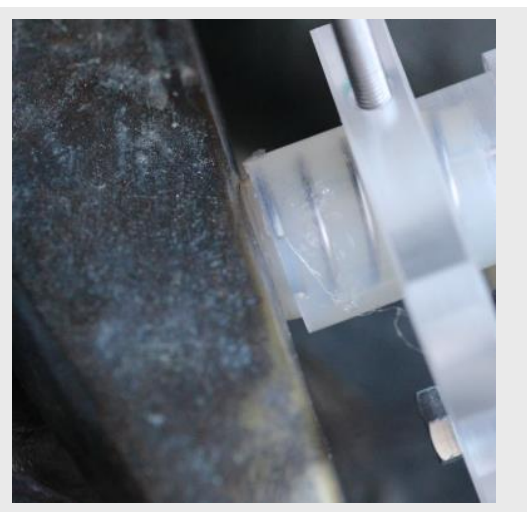

Blanca Ramírez Barat * ${ }^{[a]}$ and Emilio Cano ${ }^{[a]}$

Page No. - Page No.

Agar vs agarose gelled electrolyte for in situ corrosion studies on metallic cultural heritage 